\title{
SOBREVIVÊNCIA, CRESCIMENTO E PRODUTIVIDADE DE PLANTAS DE ERVA-MATE PRODUZIDAS POR MINIESTACAS JUVENIS E POR SEMENTES
}

\section{SURVIVAL, GROWTH AND PRODUCTIVITY OF MATÉ PLANTS PRODUCED BY SEEDLINGS AND JUVENILE MINI-CUTTINGS}

\author{
Delmar Santin ${ }^{1}$ Ivar Wendling ${ }^{2}$ Eliziane Luiza Benedetti ${ }^{3}$ Divercindo Morandi ${ }^{4}$ \\ Danilo Martin Domingos ${ }^{5}$
}

\begin{abstract}
RESUMO
O estabelecimento de ervais com mudas propagadas por semente, sem critérios de seleção de matrizes, pode levar à baixa produtividade e qualidade do produto, sendo o uso de clones selecionados uma alternativa para superação deste problema. Com base nisso, este trabalho objetivou avaliar a sobrevivência, o crescimento e a produtividade da erva-mate em plantio estabelecido com mudas propagadas por miniestaquia e por semente. $\mathrm{O}$ experimento foi instalado com quatro tratamentos: testemunha (propagada por semente) e três procedências (Bituruna, Cruz Machado e São Mateus do Sul) propagadas por miniestaquia em nível de progênies. Avaliou-se a sobrevivência durante 12 meses, o crescimento por 24 meses e a produtividade aos três e cinco anos pós-plantio. Os métodos de propagação e as procedências não influenciaram a sobrevivência, obtendo-se média de $90 \%$ nesta característica, 12 meses após o plantio. O crescimento em altura total e diâmetro do colo foi semelhante entre procedências ao longo de 24 meses, sendo apenas a procedência Bituruna significativamente inferior em altura. A produtividade da segunda colheita foi, em média, sete vezes maior que a primeira para todas as procedências. Na segunda colheita, as plantas propagadas por miniestaquia produziram mais que as propagadas por sementes. A produção de mudas de erva-mate por miniestaquia de propágulos juvenis demonstra ser adequada, pois proporcionou maior produtividade de erva-mate comercial, de folha e massa total. Ervais estabelecidos com mudas propagadas por esta tecnologia produzem mais folhas e galhos finos e menor quantidade de galhos grossos em relação às propagadas por semente.
\end{abstract}

Palavras-chave: melhoramento florestal; silvicultura clonal; produção de mudas; erva-mate comercial.

\begin{abstract}
The establishment of maté plants propagated by seeds with no genetic selection of mother trees can lead to low product productivity and quality, and the use of selected clones can be an alternative for overcoming this problem. This study aimed to evaluate the survival, growth and productivity of maté plantations established in a field with plants propagated by seeds and by mini-cuttings. Four treatments were used: control (plants propagated by seeds) and three provenances propagated by the mini-cutting technique at the progeny level (Bituruna, CruzMachadoand São Mateus do Sul, Paraná state, Brazil). There were evaluated the survival for 12

1 Engenheiro Florestal, Pós-doutorando do Programa de Pós-Graduação em Ciência do Solo da Universidade do Estado de Santa Catarina. Av. Luiz de Camões, s/n, CEP 88520-000, Lages (SC), Brasil. Bolsista CNPq. desantinflorestal@yahoo.com.br

2 Engenheiro Florestal, Dr., Pesquisador da Embrapa Florestas, Estrada da Ribeira Km 111, CEP 83411-000, Colombo (PR), Brasil. ivar@enpf.embrapa.br

3 Engenheira Agrônoma, $\mathrm{Dr}^{\mathrm{a}}$., Professora do Instituto Federal de Santa Catarina, Campus Canoinhas, Av. Expedicionários, Bairro Campo da Água Verde, CEP 89460-000, Canoinhas (SC), Brasil. elibettiagro@yahoo. com.br

4 Técnico em qualidade, Gerente de produção, M. D. Tortelli Plantas Ornamentais, Rua Antônio Macuco, 4100, Paiol Grande, CEP 83900-000, São Mateus do Sul (PR), Brasil. morandi.drenasul@yahoo.com.br

5 Engenheiro Florestal, Analista Socioambiental da Emmpresa Suzano Papel e Celulose S.A., CEP 64000-040, Teresina (PI), Brasil. quevez1982@hotmail.com
\end{abstract}

Recebido para publicação em 10/05/2011 e aceito em 21/10/2013

Ci. Fl., v. 25, n. 3, jul.-set., 2015 
months, growth for 24 months and productivity at three and five years after planting. The propagation methods and provenances did not influence the survival, obtaining the average of $90 \%$ for this feature 12 months after planting. The height and diameter were similar among provenances over 24 months, with only Bituruna provenance significantly lower in terms of height. The second harvest production was, on average, seven times higher than the first one for all provenances. In the second harvest, plants propagated by the mini-cutting technique produced more than the ones propagated by seeds. The propagation of maté by mini-cuttings of juvenile propagules proves to be appropriate because the highest commercial, leaf and total biomass yield. Maté plantations established with plants propagated by mini-cuttings produce more leaves and twigs and less thick branches, in relation to seed propagated plants.

Keywords: genetic improvement; clonal forestry; seedlings production; maté commercial production.

\section{INTRODUÇÃO}

A produção de mudas por sementes, sem critérios de seleção de matrizes, ainda é a principal forma de estabelecimento de ervais no Brasil. Esse fato reflete diretamente em plantios com crescimento desuniforme, baixa produtividade e qualidade da erva-mate comercial, que implica em menor rendimento industrial e resulta num produto industrializado com baixo valor agregado e de difícil comercialização.

$\mathrm{O}$ uso de mudas propagadas vegetativamente, com material geneticamente superior, no estabelecimento de novos ervais pode ser uma das principais alternativas, a fim de minimizar esse problema no setor ervateiro. Porém, mesmo que, desde a década de 30 , a propagação vegetativa da erva-mate tenha sido motivo de estudos (PRAT KRICUN, 1995), a adoção de protocolos de estaquia em escala comercial na produção de mudas ainda é muito limitada, principalmente referente ao rejuvenescimento de material adulto e à nutrição das estacas, o que dificulta o enraizamento das mesmas (WENDLING, 2004).

A propagação vegetativa no setor florestal já é bastante utilizada, principalmente no gênero Eucalyptus, no qual a técnica de miniestaquia é a que prevalece (XAVIER e SILVA, 2010). A formação de plantios por mudas propagadas via assexuada permitiu a clonagem em escala comercial de material genético superior, processo esse indicado como um dos principais fatores que alavancaram a eucaliptocultura brasileira nas últimas décadas e que consagrou a silvicultura clonal do eucalipto (XAVIER et al., 2009). Mas, para comprovar e validar a silvicultura clonal de qualquer espécie florestal, a avaliação da qualidade e produtividade a campo comparativa de mudas propagadas sexuada e assexuadamente é de fundamental importância
(WENDLING, 2004).

O sistema radicial das mudas propagadas vegetativamente é diferente daquele obtido a partir de sementes, sendo na maioria das vezes mais frágil, mais superficial e com ausência de raiz pivotante (WENDLING, 2004). Porém, quando na propagação vegetativa são utilizadas técnicas adequadas e propágulos juvenis, espera-se vigor radicular adequado, rendimento superior ou semelhante ao material propagado vegetativamente, em relação ao propagado sexuadamente (RESENDE et al., 1997). Convém salientar que o sucesso da implantação de ervais depende, em grande parte, da qualidade das mudas e das técnicas que visem à melhoria da multiplicação de material genético superior, sendo fundamental para obter maiores ganhos nesse setor, pois, segundo Floss (2000), mesmo que as matrizes de erva-mate apresentem baixa porcentagem de enraizamento, o método de propagação vegetativa é ainda o que pode apresentar o maior avanço dentro dos programas de melhoramento dessa espécie.

Como na cultura da erva-mate os protocolos de propagação vegetativa ainda encontram-se pouco aferidos em nível de campo e, consequentemente, as informações do comportamento de plantios oriundos de mudas propagadas via assexuada ainda são incipientes, este trabalho teve por objetivo avaliar a sobrevivência, o crescimento e a produtividade da erva-mate em plantios estabelecidos com mudas propagadas por miniestaquia e por semente.

\section{MATERIAL E MÉTODOS}

O experimento foi instalado em agosto de 2005 na propriedade do Sr. Olando Buaski, município de São Mateus do Sul - PR. O delineamento foi em blocos ao acaso, com nove 
repetições, quatro tratamentos e nove plantas úteis por parcela com duas linhas de bordadura.

Os tratamentos consistiram de uma testemunha, com mudas propagadas por sementes (T1 - procedência São Mateus do Sul (SMS/ $\mathrm{Se})$ ) e de mudas propagadas vegetativamente por miniestaquia em nível de progênies oriundas de três procedências (T2 - procedência Bituruna (Bi); T3 procedência Cruz Machado (CM) e T4 - procedência São Mateus do Sul (SMS/Mi)), todas no Estado do Paraná.

As sementes utilizadas na produção das mudas da testemunha (T1) foram coletadas das mesmas matrizes que se propagaram as mudas do T4, em fevereiro de 2004. As sementes, depois de lavadas e estratificadas em areia por cinco meses, foram semeadas em sementeira. As plântulas, ao atingirem aproximadamente $2 \mathrm{~cm}$ de altura total foram transplantadas para tubetes plásticos de $75 \mathrm{~cm}^{3}$, nos quais permaneceram até atingirem em média $9 \mathrm{~cm}$ de altura total quando foram plantadas a campo. Para a produção das mudas via miniestaquia foi adotada a metodologia descrita em Wendling et al. (2007). De forma resumida, mudas produzidas via semente (conforme procedimento descrito acima) de diferentes procedências (Bituruna, Cruz Machado e São Mateus do Sul) foram estabelecidas em sistema semi-hidropônico. Uma semana após, os seus ápices foram podados a uma altura de 5 a $8 \mathrm{~cm}$, sendo convertidas em minicepas para emissão das brotações a serem usadas como miniestacas.

As miniestacas coletadas no minijardim clonal foram enraizadas em tubetes plásticos de $75 \mathrm{~cm}^{3}$, mantidas em casa de vegetação com temperatura de $20-30{ }^{\circ} \mathrm{C}$ e umidade relativa do ar acima de $80 \%$. O substrato foi constituído de partes iguais de vermiculita, casca de arroz carbonizada e substrato comercial à base de casca de pinus. Após as mudas passarem pelos processos de enraizamento, aclimatação e rustificação, ao atingirem altura total média de $9 \mathrm{~cm}$ foram plantadas a campo.

O plantio das mudas, realizado no espaçamento de $3 \times 1,2 \mathrm{~m}$, sem adubação de base. $\mathrm{O}$ solo apresentava, na profundidade de 0-20 cm, $\mathrm{pH}\left(\mathrm{H}_{2} \mathrm{O}\right)$ de 4,5; $\mathrm{Ca}^{2+}, \mathrm{Mg}^{2+}, \mathrm{Al}^{3+}, \mathrm{H}+\mathrm{Al} \mathrm{e}$ CTCpH7,0, respectivamente, de 1,98, 0,98, 5,56, 34,50 e $37,76 \mathrm{cmol}_{\mathrm{c}} \mathrm{dm}^{-3}$; disponibilidade de P e K, respectivamente, de 1,2 e $119,0 \mathrm{mg} \mathrm{dm}^{-3}$; saturação por bases, saturação por $\mathrm{Al}$, teor de argila e de $\mathrm{MO}$, respectivamente, $8,64,63,04,44$ e 4,5\%.

Durante os primeiros 90 dias do estabelecimento das mudas, a cada 45 dias, foi efetuado coroamento com capina manual para retirada de plantas indesejáveis. A partir desta idade, a limpeza do erval foi realizada com roçadas a cada quatro meses. No inverno, utilizou-se cobertura verde com aveia-preta e nabo forrageiro.

A sobrevivência das mudas foi avaliada aos 1, 2, 3 e 12 meses após o plantio a campo. A avaliação do crescimento em altura total e diâmetro do colo foi realizada aos $0,3,12$ e 24 meses após o plantio.

A produtividade foi avaliada em duas colheitas, a primeira, três anos após o plantio (2008) e a segunda, cinco anos após o plantio (2010). $\mathrm{Na}$ primeira colheita podaram-se as plantas entre 50 a $70 \mathrm{~cm}$ de altura do solo, retirando-se aproximadamente $90 \%$ da massa verde de galhos e folhas. Na segunda colheita, a poda foi realizada da mesma forma a aproximadamente $12 \mathrm{~cm}$ de altura do broto da primeira poda, retirando-se aproximadamente $95 \%$ da massa verde crescida a partir da colheita anterior.

$\mathrm{Na}$ colheita de 2008 avaliou-se somente a produtividade de erva-mate verde comercial $(\mathrm{ECOM}=$ folha+galho fino). Já na colheita de 2010, a massa verde foi separada em folha (FO), galho fino (GF) e galho grosso (GG), no qual se avaliou, além da produtividade de ECOM e de massa total $(\mathrm{MT}=\mathrm{ECOM}+\mathrm{GG})$, o percentual de cada componente na composição da MT. Considerou-se como GF os galhos com diâmetro menor de $7 \mathrm{~mm}$, aproximadamente, e acima deste diâmetro como GG.

Na colheita de 2010 também se avaliou a qualidade da massa colhida, por meio da relação de massa verde entre componentes (ECOM/GG e FO/ GF) e, pela relação entre massa verde (V) e seca (S) dentro de cada componente (FOV/FOS, GFV/GFS e GGV/GGS). Para isso, pesou-se separadamente o GG e ECOM, coletando-se uma amostra representativa de cada componente. A amostra da ECOM foi separada em FO e GF, assim as amostras de cada componente foram secas em estufa de ventilação forçada a uma temperatura média de 65 ${ }^{\circ} \mathrm{C}$ até peso constante.

Os dados foram submetidos à análise da variância, sendo as variáveis sobrevivência, altura total e diâmetro do colo avaliadas ao longo do tempo, analisadas por regressão. Nas demais variáveis, as médias foram comparadas pelo teste de Tukey a $5 \%$ de probabilidade. 


\section{RESULTADOS E DISCUSSÃO}

\section{Sobrevivência e crescimento}

Não houve diferença na sobrevivência entre plantas propagadas por miniestaquia e por semente. A sobrevivência em todos os tratamentos reduziu ao longo do tempo, chegando ao índice mínimo de $90 \%, 12$ meses após o plantio (Figura 1A). Não ocorreu diferença significativa entre as procedências propagadas por miniestaquia e por semente para o crescimento em diâmetro do colo, porém, o mesmo aumentou ao longo do tempo em todos os tratamentos, atingindo $24 \mathrm{~mm}$ planta $^{-1}$ aos 24 meses (Figura 1B). Já a altura total foi afetada pela interação entre tempo (avaliações) e procedência. Aos 3 e 12 meses após o plantio, respectivamente, com 14 e $35 \mathrm{~cm}_{\text {planta }}{ }^{-1}$ a procedência SMS/Mi apresentou a maior altura total (Figura 1C) e, aos 24 meses do plantio, a procedência Bi com altura média de $129 \mathrm{~cm}$ planta $^{-1}$ foi inferior às demais (Figura 1D).

No estabelecimento de plantios a campo, seja com espécies nativas ou exóticas, a fase mais crítica de sobrevivência das mudas ocorre nos primeiros meses após o plantio. Ao avaliar a influência de sítios no estabelecimento de mudas de erva-mate a campo, Saidelles et al. (2003) obtiveram um índice entre 64 e $51 \%$ de sobrevivência cinco meses após o plantio. No presente trabalho, a sobrevivência aos três e doze meses após o plantio, respectivamente, de 98 e $90 \%$ pode ser considerada adequada, sem necessidade de replantio de mudas.

Considerando que mudas originadas por propagação vegetativa podem apresentar um sistema radicial mais frágil, mais superficial e com ausência de raiz pivotante (WENDLING, 2004), poderia consequentemente, reduzir a sobrevivência destas a campo, contudo, esse efeito não foi verificado. Mesmo que a propagação vegetativa possa alterar aspectos morfológicos radiculares das mudas (SASSE e SANDS, 1997; WENDLING, 2004), os aspectos fisiológicos responsáveis, principalmente, pela absorção de água e nutrientes do solo e sobrevivência das mudas a campo (CARNEIRO, 1995), aparentemente mantiveram-se equivalentes ao das mudas propagadas por semente.

$\mathrm{O}$ crescimento médio máximo em diâmetro de $24 \mathrm{~cm}_{\text {planta }}{ }^{-1} \mathrm{e}$ em altura total de $136 \mathrm{~cm}_{\text {planta }}{ }^{-1}$ aos 24 meses após o plantio é indicativo de que a erva-mate é uma espécie de crescimento lento (KAGEYAMA et al., 1991) característica de espécie clímax (CARVALHO, 2003). O comportamento da curva de crescimento do diâmetro do colo (Figura 1B) e da altura total (Figura 1C) foi semelhante. As maiores alturas verificados aos 24 meses, foram obtidos, respectivamente para CM, SMS/ Mi e SMS/Se com altura total média 139, 139 e $136 \mathrm{~cm} \mathrm{planta}^{-1}$. A igualdade no crescimento em altura na procedência SMS para os dois métodos de propagação demonstra que a miniestaquia é eficiente na propagação de erva-mate.

\section{Produtividade}

A produtividade de erva-mate comercial (ECOM) verde foi em torno de sete vezes maior na segunda colheita em relação à primeira para todas as procedências. Os tratamentos não influenciaram a produtividade na colheita de 2008, sendo a média de 1,7 $\mathrm{t} \mathrm{ha}^{-1}$. Na colheita de 2010, a produtividade de ECOM (Figura 2A), folha (Figura 2B) e massa total (MT) (Figura 2E) das plantas propagadas por miniestacas foram superiores às propagadas por semente. A maior e a menor produtividade de galho fino (GF) e galho grosso (GG) ocorreu na procedência de São Mateus propagada, respectivamente, por miniestaquia e por semente (Figura 2C e D).

Para a produtividade de erva-mate verde de ECOM na colheita de 2010, dentre as procedências propagadas por miniestaquia, a SMS/Mi obteve produtividade superior, mas, sem diferir da $\mathrm{CM}$, seguida de $\mathrm{Bi}$, respectivamente, com 14,0, 13,3 e 12,8 t ha $^{-1}$. Já a SMS/Se apresentou a menor produtividade de ECOM, com 10,7 $\mathrm{t} \mathrm{ha}^{-1}$ (Figura 2A). As procedências propagadas por miniestaquia produziram mais $\mathrm{FO}$ que a propagada por semente (Figura 2B). Na produtividade de GF (Figura 2C) e GG (Figura 2D) a procedência de São Mateus se destacou sem diferença significativa de $\mathrm{CM}$ e $\mathrm{Bi}$, porém, a propagada por miniestaquia foi superior, respectivamente com 5,0 e 12,6 $\mathrm{t} \mathrm{ha}^{-1} \mathrm{e}$, a propagada por semente inferior, respectivamente, com 3,7 e $10,5 \mathrm{t} \mathrm{ha}^{-1}$.

$\mathrm{Na}$ composição da MT, o percentual de FO e de GF não foi afetado pelos tratamentos, sendo os valores médios de todas as procedências respectivamente de 34,2 e $17,6 \%$. Já o percentual de GG foi significativamente afetado pelas procedências, com menores valores para CM e SMS/ Mi, respectivamente, com 46,9 e 47,3\%, e maior para SMS/Se com 49,7 \% de GG (Figura 3A). Para a relação $\mathrm{ECOM} / \mathrm{GG}$, as procedências propagadas por miniestaquia obtiveram os maiores valores, 

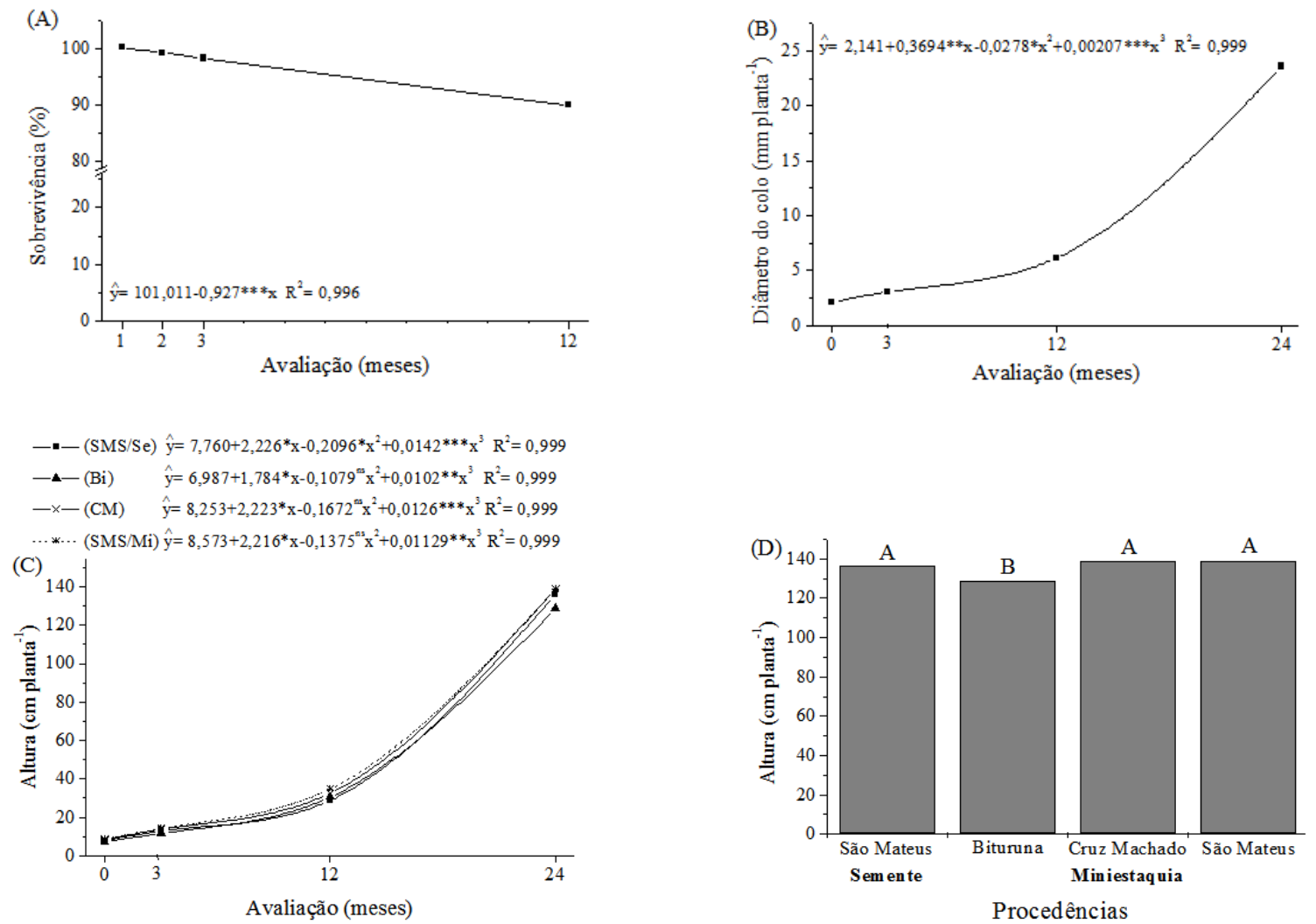

FIGURA 1: Sobrevivência (A); diâmetro do colo (B); altura total ao longo de 24 meses (C) e altura total aos 24 meses (D) de plantas de erva-mate estabelecidas com mudas propagadas vegetativamente e por sementes. $*, * *, * * * \mathrm{e}^{\text {ns }}$ significativo, respectivamente, a $5 ; 1 ; 0,1 \%$ e não significativo. Médias seguidas por mesma letra não diferem entre procedências ao nível de $5 \%$ de probabilidade.

FIGURE 1: Survival (A), collar diameter (B) and total height during 24 months (C) and height at 24 months (D) of mate plants from different provenances established by seeds and minicuttings. *, **, $* * *$ and ${ }^{\mathrm{ns}}$, respectively significant at $5,1,0.1 \%$ and not significant. Means followed by same letters do not differ between provenances at $5 \%$ probability.

sendo, a procedência de São Mateus superior à procedência propagada por semente, respectivamente com 1,2 e 1,0 (Figura 3B). $\mathrm{Na}$ relação $\mathrm{FO} / \mathrm{GF}$, novamente as procedências propagadas por miniestaquia foram superiores à propagada por semente (Figura 3C). Para a relação peso de matéria verde/seca de cada componente, não ocorreu significância entre procedências e nem entre métodos de propagação, sendo a média de todas as procedências para as relações FOV/FOS, GFV/GFS e GGV/GGS, respectivamente, de 2,2, 2,2, e 2,1. Isto indica que o teor de água na massa verde de erva-mate independe dos métodos de propagação e de procedências.

Em termos de produtividade por área de erva-mate verde comercial, todas as procedências propagadas vegetativamente são consideradas de alta tecnologia (maior que $12 \mathrm{t} \mathrm{ha}^{-1}$ ) (SBCS, 2004) mesmo o erval estando apenas na segunda colheita e, com grande potencial de aumento na produtividade. Em testes com cobertura morta em erval com cinco anos de idade e densidade de 2359 plantas ha $^{-1}$, Lourenço et al. (2001) obtiveram produtividade média de 10,2 $\mathrm{t} \mathrm{ha}^{-1}$.

Belingheri e Prat Kricun (1994) ao avaliarem a produtividade e sobrevivência da erva-mate a campo, comparando diferentes clones e progênies durante seis anos, concluíram pela superioridade das progênies em relação aos clones. No presente trabalho, as plantas provenientes de 
mudas propagadas por miniestaquia foram mais produtivas em relação às propagadas por sementes. Comportamento semelhante também foi obtido com café Conilon (Coffea canephora Pierre) (PARTELLI et al., 2006) e café Arábica (Coffea arábica L.) (CARVALHO et al., 2008) ao ser
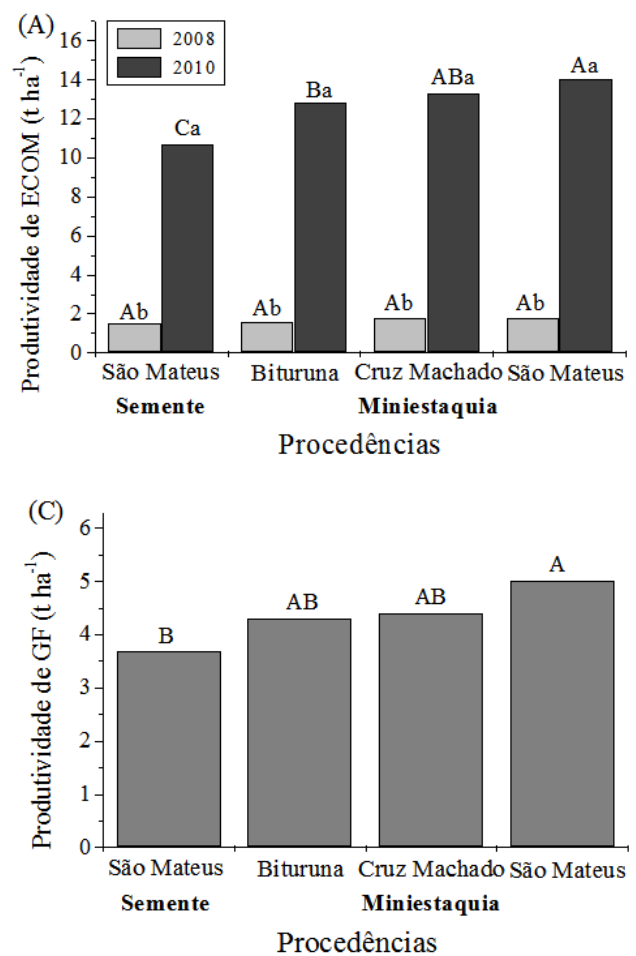

comparada a produtividade de plantas propagadas vegetativamente e por sementes. Apesar de que a propagação vegetativa possa alterar aspectos morfológicos radiculares das mudas (SASSE e SANDS, 1997; WENDLING, 2004), Partelli et al. (2006) não verificaram diferença no comprimento
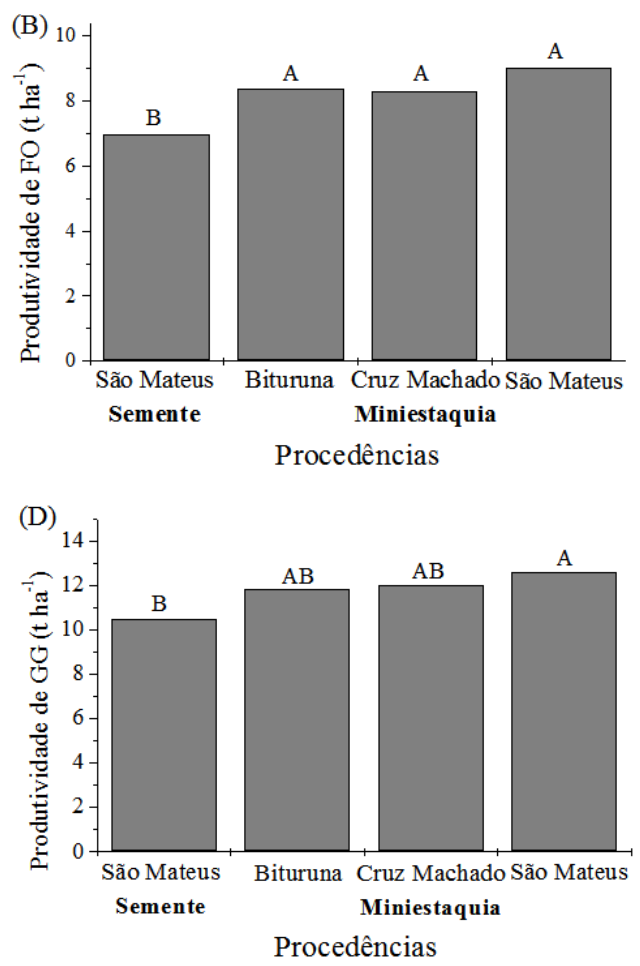

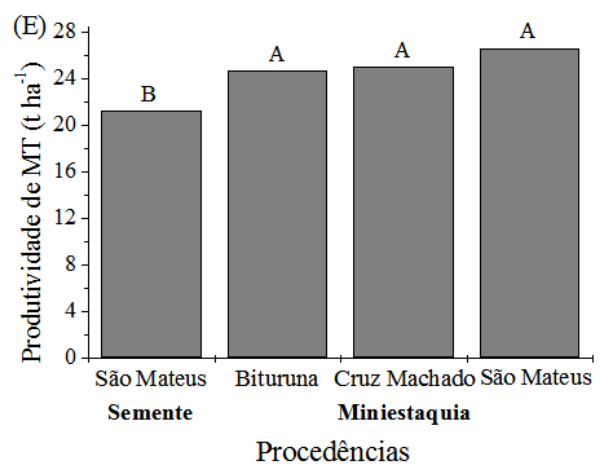

FIGURA 2: Produtividade de massa verde de erva-mate comercial (ECOM) das colheitas de 2008 e 2010 (A); produtividade de massa verde de folha (FO) (B), galho fino (GF) (C), galho grosso (GG) (D) e massa total (MT) da colheita de 2010 (E) em erval estabelecido com mudas propagadas por miniestaquia e por sementes. Médias seguidas por mesma letra maiúscula não diferem entre procedências (A, B, C, D e E) e mesma letra minúscula não diferem dentro de cada procedência (A) ao nível de $5 \%$ de probabilidade.

FIGURE 2: Green mass production of commercial mate (ECOM) of 2008 and 2010 harvests (A); green leaf mass production (FO) (B), thin twig (GF) (C), large branch (GG) (D) and total green mass (E) of the 2010 harvest of mate established with plants propagated by seeds and by minicuttings. Means followed by same capital letter do not differ between provenances (A, $\mathrm{B}, \mathrm{C}, \mathrm{D}$ and $\mathrm{E}$ ) and the same lower case letter within provenances (A) at the $5 \%$ probability. 

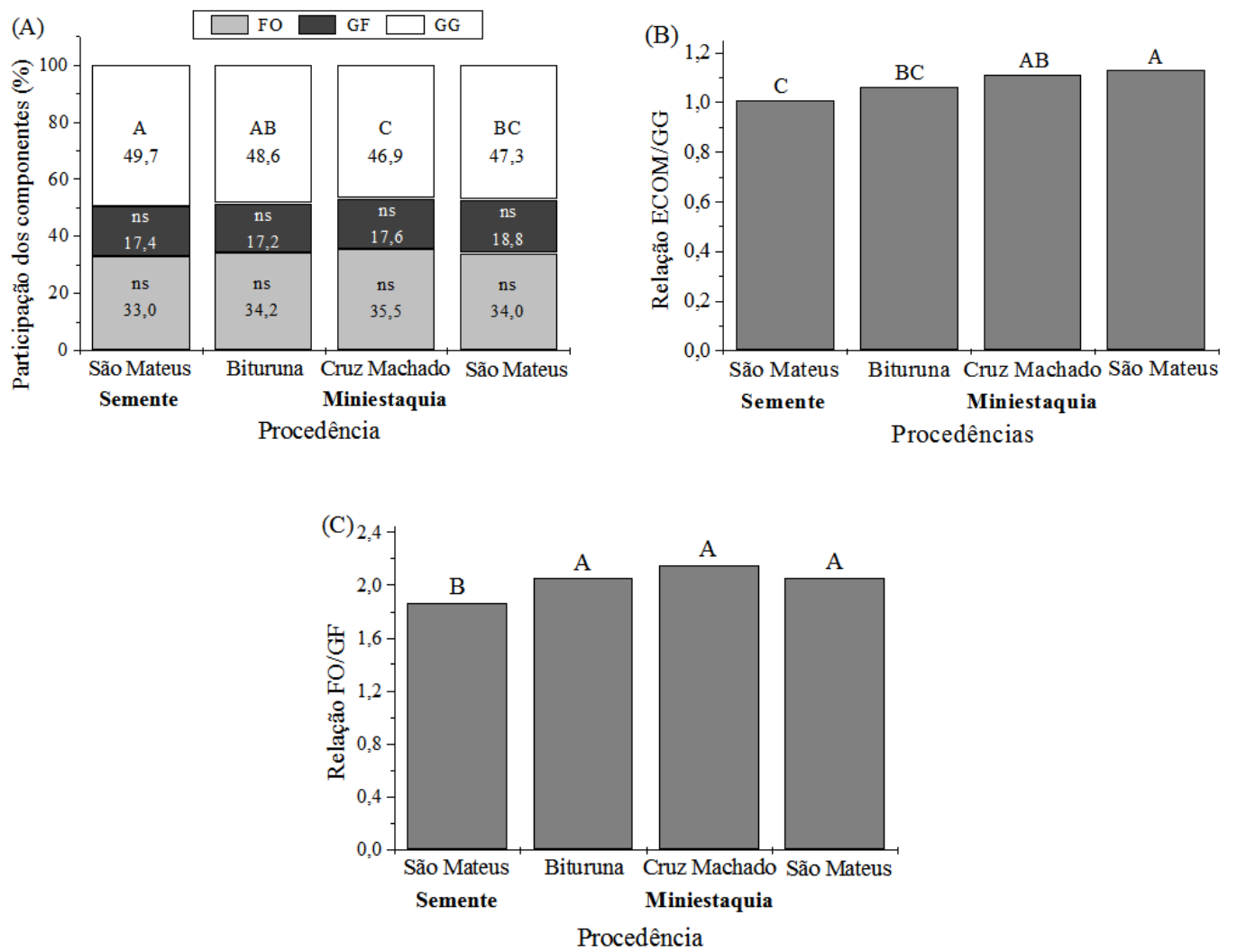

FIGURA 3: Percentual de folha (FO), galho fino (GF) e galho grosso (GG) (A); relação entre erva-mate comercial (ECOM) e GG (B) e FO e GF (C) da massa verde da colheita de 2010 em erval estabelecido com mudas propagadas por miniestaquia e semente. Médias seguidas por mesma letra não diferem entre procedências e ${ }^{\text {ns }}$ não significativo ao nível de $5 \%$ de probabilidade.

FIGURA 3: Percentage of leaf (FO), thing twig (GF) and thick branch (GG) (A); relationship between commercial mate (ECOM) and GG (B) and ratio of FO and GF (C) of green mass harvested in 2010 in mate plants propagated by seeds and by minicuttings. Means followed by same letter do not differ between provenances and ${ }^{\text {ns }}$ not significant at $5 \%$ probability.

e área superficial de raízes entre plantas de café Conilon propagadas por diferentes métodos, atribuindo a superioridade de produtividade às plantas propagadas por estaquia ao fator genético e à maturidade fisiológica das plantas. Considerando que o sistema radicular das plantas apresenta características diferenciadas de acordo com a espécie (LYNCH, 1995), não se pode descartar a hipótese de que para erva-mate, a propagação vegetativa possa influenciar positivamente o desenvolvimento do sistema radicial das plantas, desde que se lancem mão das técnicas recomendadas e material juvenil. A superioridade na produtividade de ECOM, FO e MT das plantas propagadas vegetativamente pode estar relacionada, em parte, ao sistema radicial. Isso porque na propagação vegetativa muitas espécies podem desenvolver um sistema radicial mais fasciculado (OLIVEIRA et al., 2001) com maior volume de raízes finas, as quais, são importantes na absorção de nutrientes e água (GONÇALVES e MELLO, 2005). Esta hipótese pode ser verificada, principalmente, pela superioridade na maioria das variáveis (Figuras 2A, B, C, D e E) das plantas propagadas por miniestaquia, dentro da mesma procedência (SMS), que elimina o fator ambiente e genótipo. Esses resultados, aliado ao fato da erva-mate permanecer produtiva por mais de 100 anos (SANTIN, 2008), merece uma investigação em longo prazo do sistema radicial de plantas propagadas via assexuada. 
A tendência a maiores valores para todas as variáveis referentes à produtividade de massa verde (Figura 2), observadas na procedência São Mateus propagada por miniestaquia, comparada às demais procedências com mesmo método de propagação, pode estar relacionado ao fator local, já que as demais procedências são oriundas de locais diferentes ao do experimento. A adaptação a diferentes solos, dentre outros fatores, pode dificultar a expressão do potencial produtivo de essências florestais nativas (FURTINI NETO et al., 1999), que neste caso, a procedência São Mateus foi favorecida por já estar adaptada ao ambiente local.

Considerando que a produtividade de ECOM do erval foi alta (CQFS-RS/SC, 2004), a relação entre $\mathrm{ECOM} / \mathrm{GG}$ próximo de 1,0 pode ser indicativo de produtividade adequada e, valor maior que 1,0 alta produtividade. Isso pode ser verificado pelo aumento de 0,2 no valor da relação entre ECOM/ GG para a procedência SMS/Mi, comparada com SMS/Se (Figura 2B), que refletiu no acréscimo de 3,3 $\mathrm{t} \mathrm{ha}^{-1}$ de produtividade de ECOM. Porém, este comportamento não pode ser generalizado, pois, a FO e o GF são suportados pelo GG, assim, o valor desta relação como indicativo de alta produtividade, não deve estar além de 1,2. Da mesma forma, vale para a idade do erval, pois, a relação ECOM/GG deve mudar juntamente com a mudança da estrutura e forma da copa das plantas à medida que a idade do erval avança.

Nos programas de melhoramento de ervamate, a produção de massa verde, desfolhamento, tipo e arquitetura de ramos são as principais características relacionadas à produtividade (RESENDE et al., 2000). A relação ECOM/GG, que é um parâmetro de rendimento da erva-mate ao produtor e, as relações FO/GF, FOV/FOS e GFV/ GFS que demonstram o rendimento da ECOM na indústria, são características que merecem atenção. Isso porque ervais com mesmo potencial de produtividade de massa verde, mas com diferença de 0,1 no valor da relação ECOM/GG, pode significar um aumento de $5 \%$ na produtividade de ECOM. Essa mesma analogia vale para a FO/GF e massa verde/massa seca, na qual matéria-prima com melhor qualidade é reflexo de maiores valores de $\mathrm{FO} / \mathrm{GF}$, assim como, de menores valores da relação massa verde/massa seca. Isso reflete consequentemente, em matéria-prima e produto industrializado de maior valor comercial. Desta forma, essas variáveis devem ser levadas em consideração principalmente na seleção de matrizes.
A superioridade de produtividade de ervamate comercial das procedências propagadas por miniestaquia na colheita de 2010 é percebida, principalmente pela diferença de $24 \%$ obtida na procedência de São Mateus em relação às mudas propagadas por sementes (Figura 2A). Apesar de que o erval em estudo ainda é jovem, os resultados demonstram claramente que a propagação vegetativa de mudas com material selecionado, no estabelecimento de plantios de erva-mate, é uma excelente ferramenta para a melhoria da produtividade.

\section{CONCLUSÕES}

Ervais estabelecidos com mudas propagadas por miniestaquia apresentam alto índice de sobrevivência, bom crescimento, e alta produtividade de erva-mate.

A propagação vegetativa de mudas oriundas de sementes (progênies) pode resultar em aumento de produtividade de erva-mate.

A seleção de matrizes de diferentes procedências permite identificar características específicas relacionadas à produtividade e à qualidade da erva-mate que podem proporcionar maior rentabilidade ao produtor e a indústria.

\section{AGRADECIMENTOS}

Ao Sr. Olando Buaski pela disponibilidade da área e manutenção do experimento e a Empresa Baldo S.A., pelo suporte estrutural para a realização desse trabalho.

\section{REFERÊNCIAS BIBLIOGRÁFICAS}

BELINGHERI, L. D.; PRAT KRICUN, S. D. Evaluacion de los rendimientos de clones y progenies de yerba mate (Ilex paraguariensis $\mathrm{St}$. Hil.). Cerro Azul: INTA, Estación Experimental Agropecuaria Cerro Azul, 1994. 17 p.

CARNEIRO, J. G. A. Produção e controle de qualidade de mudas florestais. Curitiba: UFPR/FUPEF, 1995. $451 \mathrm{p}$.

CARVALHO, M. et al. Comportamento em condições de campo de cafeeiros (Coffea arábica L.) propagados vegetativamente e por semeadura. Coffe e Science, Lavras, v. 3, n. 2, p. 108-114, jul./dez. 2008.

CARVALHO, P. E. R. Espécies arbóreas brasileiras. Colombo: Embrapa Florestas, 2003, 
$1039 \mathrm{p}$.

FLOSS, P. A. Programa de melhoramento genético da erva-mate na Epagri. In: CONGRESSO SULAMERICANO DA ERVA-MATE, 1., REUNIÃO TÉCNICA DO CONE SUL SOBRE A CULTURA DA ERVA-MATE, 2., 1997, Colombo. Anais... 1997. p. 279-284.

COMISSÃO DE QUÍMICA E FERTILIDADE DO SOLO - CQFS-RS/SC. Manual de adubação e calagem para os Estados do Rio Grande do Sul e Santa Catarina. 10. ed. Porto Alegre, Sociedade Brasileira de Ciência do Solo/Núcleo Regional Sul, 2004. 400 p.

FURTINI NETO, A. E. et al. Acidez do solo, crescimento e nutrição mineral de algumas espécies arbóreas, na fase de muda. Cerne, Lavras, v. 5, n. 2, p. 01-12, 1999.

GONÇALVES, J. L. M.; MELLO, S. L. M. O sistema radicular das árvores. In: GONÇALVES, J. L. M.; BENEDETTI, V. Nutrição e fertilização florestal. Piracicaba: IPEF, 2005. p. 219-267.

KAGEYAMA, P. Y. et al. Diretrizes para a reconstituição da vegetação florestal ripária de uma área piloto da Bacia de Guarapiranga. Relatório apresentado à Coordenadoria de Planejamento Ambiental da Secretaria de Estado do Meio Ambiente: Piracicaba, 1991. 40 p.

LYNCH, L. Root architecture and plant productivity. Plant Physiology, v. 109, p. 7-13, 1995.

LOURENÇO, R. S. et al. Influência da cobertura morta na produtividade da erva-mate. Boletim de Pesquisa Florestal, Colombo, n. 43, p. 113-122, jul./dez.2001.

PARTELLI, F. L. et al. Produção e desenvolvimento radicular de plantas de café 'Conilon' propagadas por sementes e por estacas. Pesquisa Agropecuária Brasileira, Brasília, v. 41, n. 6, p. 949-954, 2006.

OLIVEIRA, M. C. et al. Enraizamento de estacas para produção de mudas de espécies nativas de mata de galeria. Brasilia, 2001. 4 p. (Recomendação Técnica 41)

PRAT KRICUN, S. D. Propagación vegetativa de plantas adultas de Yerba mate. In: WINGE, H. et al. (org). Erva-mate: biologia e cultura no Cone Sul,
Porto Alegre, Ed. UFRGS, 137-150. 1995.

RESENDE, M. D. V. et al. Estratégias para o melhoramento genético da erva-mate. In: CONGRESSO SUL-AMERICANO DA ERVAMATE, 1.; REUNIÃO TÉCNICA DO CONE SUL SOBRE A CULTURA DA ERVA-MATE, 1997, Curitiba. Anais... Colombo: Embrapa-CNPF, 1997, p. 243-266.

RESENDE, M. D. V. et al. Programa de melhoramento da erva-mate coordenado pela EMBRAPA: resultados da avaliação genética de populações, progênies, indivíduos e clones. Colombo: Embrapa Floresta, 2000. n. 43, (Circular Técnica, 65).

SAIDELLES, F. L. F. et al. Crescimento inicial de mudas de erva-mate (Ilex paraguariensis St. Hil.) em três classes de solos, na região central do Rio Grande do Sul. Ciência Florestal, Santa Maria, v. 13, n. 2, p. 17-25, 2003.

SANTIN, D. Produtividade, teor de minerais, cafeína e teobromina em erva-mate adensada e adubada quimicamente. 2008. 114 f. Dissertação (Mestrado em Ciência do Solo) - Universidade Federal do Paraná, Curitiba, 2008.

SASSE, J.; SANDS, R. Configuration and development of root systems of cuttings and seeding of Eucalyptus globulus. New Forests, Netherlands, v. 14, n. 2, p. 85-105.1997.

WENDLING, I. Propagação vegetativa de ervamate (Ilex paraguariensis Saint Hilaire): estado da arte e tendências futuras. Colombo: Embrapa Florestas, 2004, 46 p. (Documentos, 91).

WENDLING, I. et al. Produção e sobrevivência de miniestacas e minicepas de erva-mate cultivadas em sistema semi-hidropônico. Pesquisa Agropecuária Brasileira, Brasília, v. 42, n. 2, p. 289-292, 2007.

XAVIER, A.; SILVA, R. L. Evolución de la silvicultura clonal de Eucalyptus en Brasil. Agronomia Costarricense, Costa Rica, v. 34, n. 1, p. 93-98, 2010.

XAVIER, A.; WENDLING, I.; SILVA, R. L .Silvicultura Clonal: princípios e técnicas. 1. ed. Viçosa: UFV, 2009. 272 p. v. 1. 